\title{
I 42 A new approach towards improved visualization of myocardial edema using T2-weighted imaging
} Myra S Cocker*1, Oliver Strohm¹, Jordin D Green², Steven M Shea ${ }^{3}$, Hassan Abdel-Aty ${ }^{4}$ and Matthias G Friedrich ${ }^{1}$

\author{
Address: ${ }^{1}$ Libin Cardiovascular Institute at the University of Calgary, Stephenson Cardiovascular Magnetic Resonance Centre, Calgary, AB, Canada, \\ ${ }^{2}$ Siemens Medical Solutions, Calgary, Canada, Calgary, AB, Canada, ${ }^{3}$ Siemens Corporate Research, Evanston, IL, USA and ${ }^{4}$ Franz-Volhard Klinik, \\ Charite Universitatsmedizin, Berlin, Germany \\ * Corresponding author
}

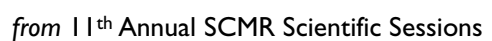
Los Angeles, CA, USA. I-3 February 2008

Published: 22 October 2008

Journal of Cardiovascular Magnetic Resonance 2008, I0(Suppl I):A267 doi:10.1 I86/I532-429X-I0-SI-A267

This abstract is available from: http://jcmr-online.com/content//0/SI/A267

(c) 2008 Cocker et al; licensee BioMed Central Ltd.

\section{Background}

Imaging edema with T2-weighted STIR (Short T1 Inversion Recovery) often results in poor image quality due to low signal-to-noise ratio (SNR) and cardiac motion sensitivity. An alternative option is to image with AASPIR (Asymmetric Adiabatic Spectral Inversion Recovery) [1,2] turbo spin echo (TSE). Non-selective spectral excitation of only the fat signal may improve SNR and reduce motion sensitivity. Therefore, we assessed image quality and signal intensity of AASPIR compared with STIR for cardiovascular magnetic resonance (CMR) imaging of the myocardium.

\section{Methods}

We studied 30 patients ( 21 males, $46 \pm 17$ years), referred for cardiovascular magnetic resonance scans for myocardial tissue characterization using both STIR and AASPIR preparations for T2-weighted TSE imaging. All images were acquired with a $1.5 \mathrm{~T}$ scanner (Avanto, Siemens Medical Solutions, Erlangen, Germany). Image acquisition was performed in basal and mid-ventricular short axis slices, and apical slices were acquired only if good image quality could be obtained. Signal intensity (SI) of left ventricular myocardium was normalized to skeletal muscle, generating a T2 signal intensity ratio (SIR). Moreover, the SI of myocardium was related to noise, as defined by the mean SI of a region of interest anterior to the chest wall, generating a SNR. Two independent observers assessed image quality and artifact suppression using a 5-class score system.

\section{Results}

AASPIR showed a higher SNR for basal (42.4 vs. 27.0, p < $0.001)$, and mid- (52.8 vs. $31.2, \mathrm{p}<0.001)$, and apical (55 vs. $27.0, \mathrm{p}<0.001$ ) ventricular myocardium (Figure 1 ), a higher image quality and a more consistent suppression of artifacts (Figure 2). SIR did not differ between STIR and AASPIR imaging (1.633 vs. $1.626, \mathrm{p}=0.845)$.

\section{Conclusion}

Our findings support the implementation of an AASPIR instead of a STIR sequence for T2-weighted CMR imaging, with increased SNR, and improved image quality.

\section{References \\ I. Rosenfeld D, et al:: Magn Reson Med 1997, 37:793-80I. \\ 2. Shea SM, et al.: ISMRM 2007:2475.}




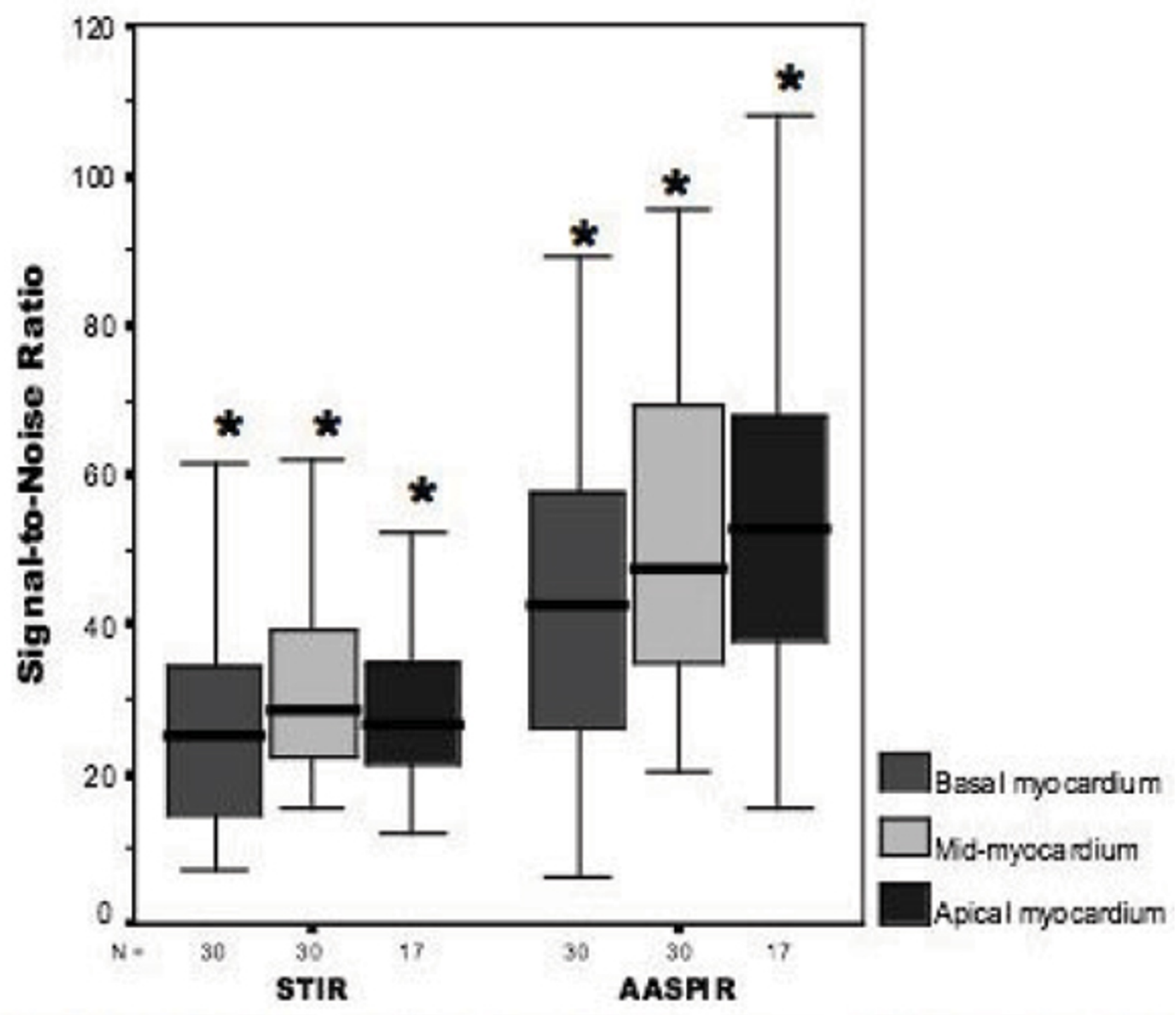

Figure I

Imrpoved signal-to-noise ratios for basal, mid- and apical myocardium with AASPIR T2-weighted imaging. * $\mathrm{p} \leq 0.05$. 


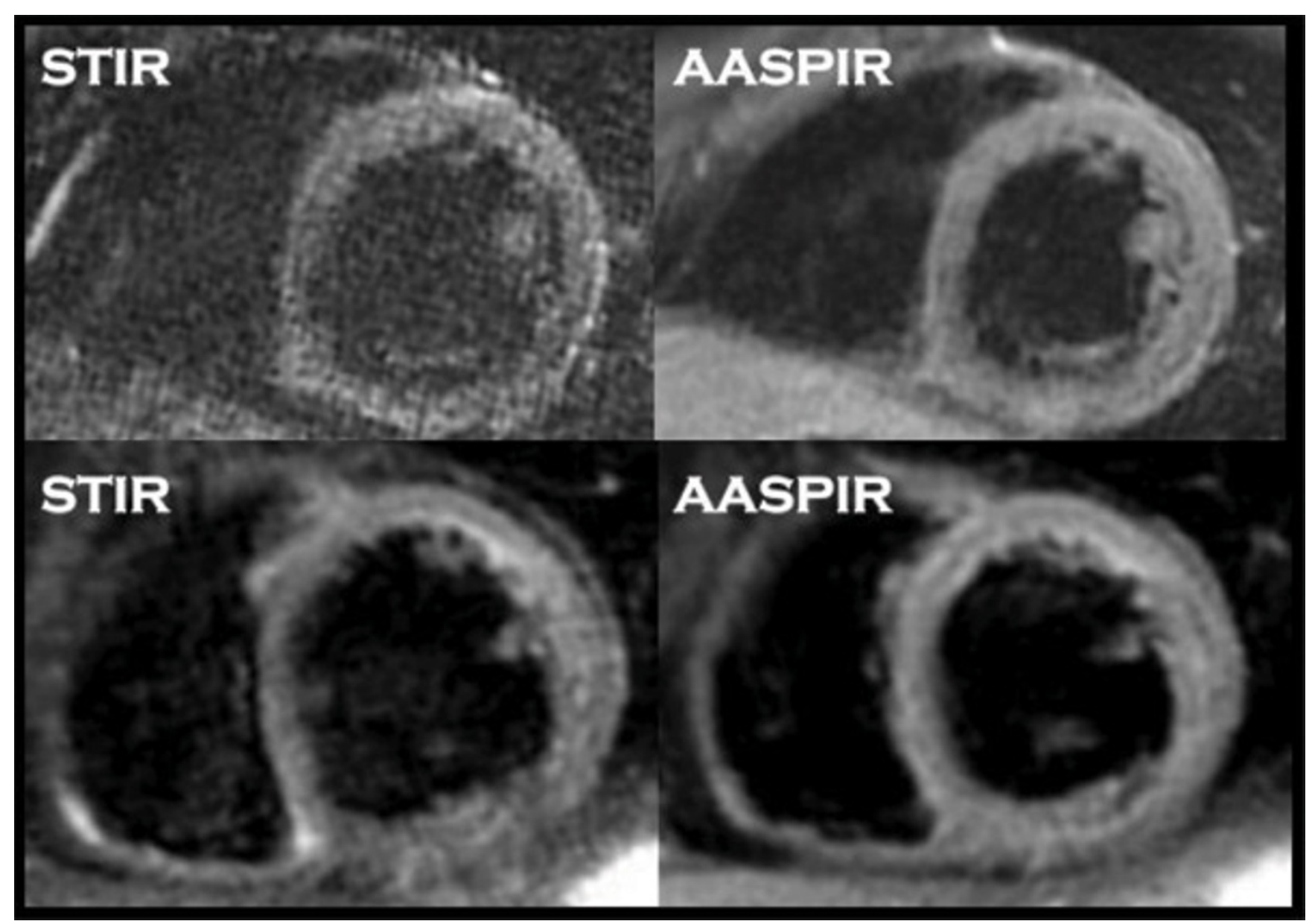

Figure 2

Improved image quality with T2-weighted AASPIR imaging compared to STIR.

\section{Publish with BioMed Central and every scientist can read your work free of charge}

"BioMed Central will be the most significant development for disseminating the results of biomedical research in our lifetime. " Sir Paul Nurse, Cancer Research UK

Your research papers will be:

- available free of charge to the entire biomedical community

- peer reviewed and published immediately upon acceptance

- cited in PubMed and archived on PubMed Central

- yours - you keep the copyright 